\title{
Detection of dengue, west Nile virus, rickettsiosis and leptospirosis by a new real-time PCR strategy
}

\author{
Daniel García-Ruíz', Marco A. Martínez-Guzmán', Albertina Cárdenas-Vargas', Erika Marino-Marmolejo', \\ Abel Gutiérrez-Ortega', Esteban González-Díaz², Rayo Morfin-Otero², Eduardo Rodríguez-Noriega², \\ Hector Pérez-Gómez ${ }^{2}$ and Darwin Elizondo-Quiroga ${ }^{{ }^{*}}$
}

\begin{abstract}
Dengue virus (DENV) infection causes sudden fever along with several nonspecific signs and symptoms and in severe cases, death. DENV is transmitted to people by Aedes aegypti and Ae. albopictus mosquitoes, whose populations increase during rainy season. West Nile Virus (WNV), Rickettsia spp. and Leptospira spp. are fever-causing pathogens that share many of the initial symptoms of DENV infection and also thrive in the rainy season. Outbreaks in some regions may be due to any of these pathogens that can co-circulate. Plus, they are clinically indistinguishable until severe symptoms appear, even though these diseases should be treated differently. An effective differential diagnosis would help clinicians and vector control departments to make right decisions for control and treatment of these diseases. Therefore, we developed four different SYBR green ${ }^{\circledR}$-based reverse transcription quantitative PCR (RT-qPCR) assays for simultaneous detection of DENV, WNV, Rickettsia spp. and Leptospira spp. The assay has been optimized to yield results in less than $1 \mathrm{~h}$; and in order to reduce contamination risk, all reagents were premixed and lyophilized on 96 well plates and thus only requires the addition of water and total nucleic acids from the sample. Sensitivities of the assays were less than 100 copies of nucleic acid targeted for these four pathogens. Assays did not show cross reactivity with any of the four pathogens nor to human nucleic acids. We are presenting a sensitive and selective kit that detects four relevant pathogens from tropical regions, that is quick, cost-effective and easy to use.
\end{abstract}

Keywords: Dengue, West Nile Virus, Rickettsia, Leptospira, Real time PCR

\section{Background}

Dengue fever, West Nile fever, rickettsiosis and leptospirosis are re-emerging infectious diseases worldwide and year-by-year cases are reported in Latin America and other regions, where efforts for epidemiologic surveillance in some cases have limited success. These pathogens produce similar symptoms at the onset of the disease, including: sudden high fever, myalgia, and retro-orbital pain. Despite the presentation of similar

\footnotetext{
${ }^{*}$ Correspondence: delizondo@ciatej.mx

${ }^{1}$ Dirección de Biotecnología Médica y Farmacéutica, Centro de Investigación y Asistencia en Tecnología y Diseño del Estado de Jalisco (CIATEJ), Avenida Normalistas No. 800, Colinas de la Normal, C.P. 44270 Guadalajara, Jalisco, Mexico

Full list of author information is available at the end of the article
}

symptoms, these diseases progress to different severe outcomes (Bäck and Lundkvist 2013; Levett 2001; Levett et al. 2000; Mahajan 2012; Petersen and Marfin 2002; Sahni and Rydkina 2009). Considering this and also that these agents can share ecological niches, there is potential risk for misdiagnosis and hence silent circulation of some of these pathogens in the aforementioned regions.

The World Health Organization (WHO) classifies dengue disease as classic dengue fever and severe dengue fever. Classic dengue fever includes the symptoms described previously. Severe dengue fever is further divided according to severity into Dengue Hemorrhagic Fever (DHF) and Dengue Shock Syndrome (DSS) (World Health Organization 2009). Infections with WNV in some cases can be fatal; its fever can evolve into a 
neuroinvasive disease in which paralysis, meningoencephalitis and poliomyelitis-like syndrome may occur (Colpitts et al. 2012). Rickettsia spp. replicate inside vascular endothelial cells, causing vascular damage and they can also reach the endothelium of liver, kidneys, pancreas and other organs resulting in internal bleeding (Mahajan 2012). Leptospira spp. are spiroquetes that can rapidly move through the blood, reaching the kidneys, heart, lungs and liver. These bacteria damage tissues while moving within organs and can cause multiorganic failure in a few weeks (Levett 2001).

The potentially lethal outcomes of these diseases underline the need for an early differential diagnostic test. Rather than serological assays, molecular technics are required for accurate and sensitive diagnosis, but these technics are time-consuming, expensive, require highly-trained personnel and are not readily available (Cota et al. 2012). Furthermore, an important drawback of molecular technics is the low stability of reagents, particularly enzymes. Lyophilization of reagents has proved to enhance the stability of enzymes at room temperature thus eliminating any special requirements for storage (Lins et al. 2004). Some previously reported protocols for PCR have been designed where all reagents, except the sample, have been lyophilized and tested in-field (Howson et al. 2015; Kamau et al. 2014; Lee et al. 2011). Cryoprotectants like saccharides can be added to enhance the stability. For instance, trehalose (a glucose disaccharide) has been tested and found to have properties that aids to maintain the native structure and function of several proteins (Ohtake and Wang 2011).

Although several molecular assays have been developed for diagnosis of each disease herein described (Denison et al. 2014; Lai et al. 2007; Lee et al. 2011; Li et al. 2011; Papin et al. 2004), none of them have been designed to diagnose these four pathogens simultaneously. The aim of this study was to develop a safe, reproducible, stable, quick and easy-to-use simultaneous differential diagnostic test, which would be able to detect four fever-causing agents that could co-circulate in the same geographic area, using primers for each disease and SYBR Green as a fluorescent dye in order to make it cost-effective.

\section{Methods}

\section{Design of primers}

Primers for WNV, Rickettsia spp. and Leptospira spp. were designed using CLC Main Workbench 5 with alignments of highly conserved regions selected for each agent as target sequences. For the alignment of WNV we used eight partial sequences of the envelope protein. For Leptospira spp., we aligned 97 sequences of the $16 \mathrm{~S}$ ribosomal RNA gene from seven species and for Rickettsia spp., 24 sequences of $g l t A$ gene from 11 species were aligned. For DENV we used primers reported by Lai et al. capable of detecting a conserved region across the four serotypes (Lai et al. 2007). All primers were synthesized by IDT $^{\mathrm{TM}}$ (Coralville USA). Primers are shown in Table 1.

\section{RT-qPCR design}

RT-qPCRs assays were carried out in a Light Cycler 480 II PCR platform (Roche Diagnostics, Penzberg, Germany), using QuantiFast SYBR Green RT-qPCR Kit (Qiagen ${ }^{\mathrm{TM}}$ Hilden Germany). In order to simultaneously detect any of the four pathogens in a sample, a 96-well plate was used with a distribution of each set of primers per agent in a different well of the plate, plus the Master Mix of the QuantiFast kit, and adding $5 \mu \mathrm{L}$ of total nucleic acids extracted from the sample in each of these four wells; additionally, a no template control was added and positive controls wells were also included (Fig. 1). The concentration of primers were $80 \mathrm{nM}$ forward and $130 \mathrm{nM}$ reverse for DENV, $60 \mathrm{nM}$ forward and $120 \mathrm{nM}$ reverse for WNV, $1000 \mathrm{nM}$ for both primers for Rickettsia and for Leptospira (Table 2). The RT-qPCR conditions were $50^{\circ} \mathrm{C}$ for $10 \mathrm{~min}$, then $5 \mathrm{~min}$ at $95^{\circ} \mathrm{C}$ followed by 40 cycles of $95{ }^{\circ} \mathrm{C}$ for $10 \mathrm{~s}$ and $60{ }^{\circ} \mathrm{C}$ for $30 \mathrm{~s}$; fluorescence quantification was performed during the annealing step (Table 2).

\section{Specimens, samples and nucleic acids extraction}

For the viral agents positive controls construction, RNA from a serum sample confirmed as DENV-2 by the Health Secretariat of the state of Guerrero, and a WNV horse vaccine donated by the Mexican National Polytechnic Institute, were extracted, using a QiAmp Viral RNA Mini Kit (Qiagen ${ }^{\mathrm{TM}}$ Hilden Germany) according to the manufacturer's instructions. In brief, directly from $140 \mu \mathrm{L}$ of each specimen, RNAs were extracted and eluted in $60 \mu \mathrm{L}$ of the elution buffer. Rickettsia canadensis (CA410 VR-1444) and Leptospira interrogans (Stimson) Wenyon $\left(A T C C^{\circledR} 23478^{\mathrm{TM}}\right)$ were purchased from the American Type Culture Collection (ATCC). A $25 \mathrm{~cm}^{2}$ tissue flask culture containing fresh Vero cells $\left(\right.$ ATCC $^{\circledR}$ CCL-81 ${ }^{\mathrm{TM}}$ ) was inoculated with $R$. canadensis and maintained at $37^{\circ} \mathrm{C}$ with DMEM (GIBCO) medium with $1 \%$ fetal bovine serum. Infected cell cultures were scraped from the flask after 11 days of culture and centrifuged along with the supernatant at $10,000 \times g$ for $10 \mathrm{~min}$. $L$. interrogans was incubated in $5 \mathrm{~mL}$ of $\mathrm{EMJH}$ medium at $28{ }^{\circ} \mathrm{C}$ for 7 days and then centrifuged at $4000 \times g$ for $5 \mathrm{~min}$. Pellets for both bacteria were collected and DNA was extracted using QIAmp DNA Mini Kit (Qiagen ${ }^{\text {TM }}$ Hilden, Germany) according to the manufacturer's instructions. In brief, DNAs were extracted and eluted in $200 \mu \mathrm{L}$ of the elution buffer directly from $200 \mu \mathrm{L}$ of each specimen. 
Table 1 Characteristics and concentration of primers used in this work

\begin{tabular}{|c|c|c|c|c|c|c|}
\hline $\begin{array}{l}\text { Primer } \\
\text { name }\end{array}$ & Primer sequence & $\begin{array}{l}\text { Length } \\
(\mathrm{pb})\end{array}$ & $\operatorname{Tm}\left({ }^{\circ} \mathrm{C}\right)$ & $\begin{array}{l}\Delta G \text { of homodimers } \\
\text { at } 3^{\prime}(\mathrm{Kcal} / \mathrm{mol})\end{array}$ & $\begin{array}{l}\Delta \mathrm{G} \text { of heterodimers } \\
\text { at } 3^{\prime}(\mathrm{Kcal} / \mathrm{mol})\end{array}$ & $\begin{array}{l}\text { Conc. } \\
\text { (nM) }\end{array}$ \\
\hline DENV-For & TTGAGTAAACYRTGCTGCCTGTAGCTC & 27 & $58.4-62.3$ & -6.34 & -6.34 & 80 \\
\hline DENV-Rev & GAGACAGCAGGATCTCTGGTCTYTC & 25 & $58.6-59.8$ & -6.28 & & 130 \\
\hline WNV-For & GGTGGATTTGGTTCTCGAAGGCG & 23 & 60.4 & -3.61 & -3.61 & 60 \\
\hline WNV-Rev & AGGGTCAGCACGTTTGTCATTGTG & 24 & 60 & -1.95 & & 120 \\
\hline RICK-For & TATGCTTGCGGCTGTCGGTTCTC & 23 & 61.7 & -3.14 & -3.61 & 1000 \\
\hline RICK-Rev & TTGCGGTAAGTTCGTAGTCTGCTTCTT & 27 & 59.9 & -3.61 & & 1000 \\
\hline LEP-For & AGCAGCCGCGGTAATACGTATGG & 23 & 61.3 & -3.14 & -3.55 & 1000 \\
\hline LEP-Rev & TTTAGGGCGTGGATTACTGGGG & 22 & 59 & -0.96 & & 1000 \\
\hline
\end{tabular}

Tm melting temperature, Conc. concentration used in this study, $\Delta G$ Gibbs energy

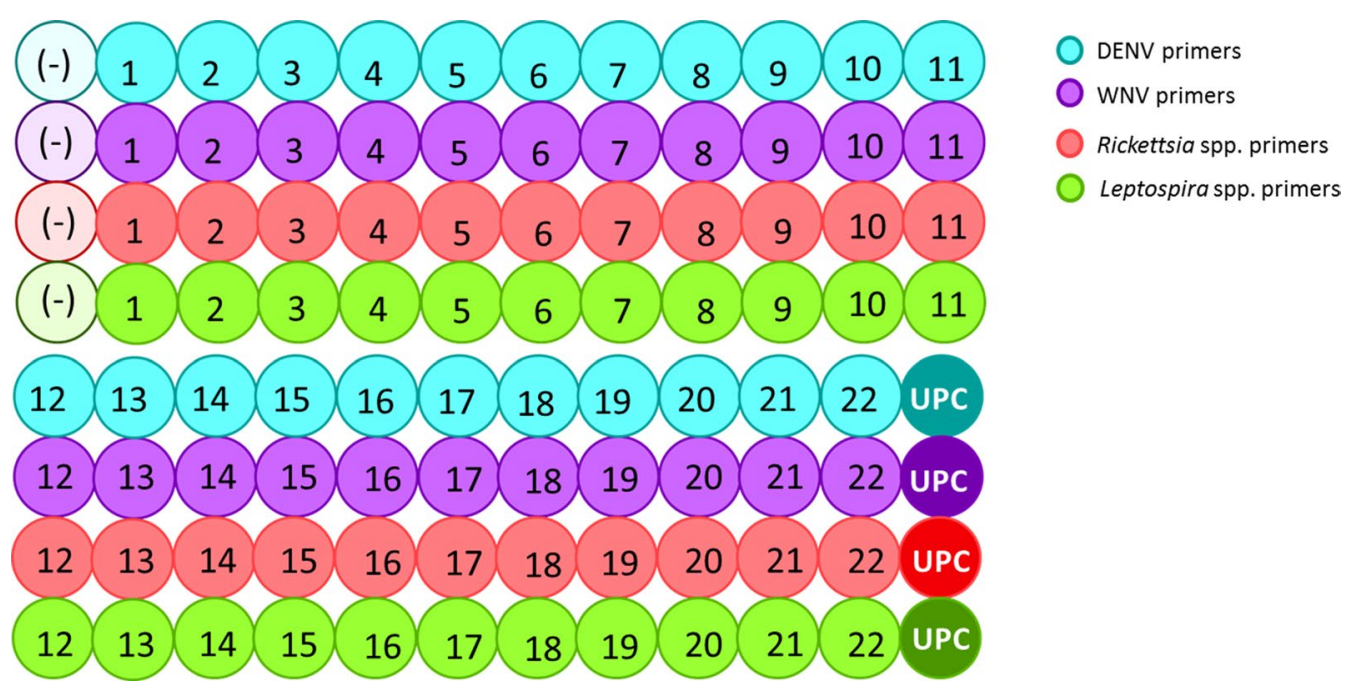

Fig. 1 Primer distribution in a 96-well PCR plate. All the wells contain a QuantiFast SYBR Green RT-qPCR Master Mix. Additionally, the wells contain the primers for DENV (b/ue), WNV (violet), Rickettsia spp. (red) and Leptospira spp. (green). Numbers represent the sample that must be added to each set of four wells. The plate includes a set of four wells for negative control [light-colored wells with a "(-)"sign] and another for the Universal Positive Control (dark-colored wells with "UPC")

In order to pre-validate the diagnostic strategy, sera samples from patients showing dengue-like symptoms (less than 5 days since fever onset), were provided by Hospital Civil de Guadalajara Fray Antonio Alcalde. The samples were managed in cold conditions at all times and processed in a laminar flow cabinet Class II Type A2 in BSL2 facilities until inactivation. Total nucleic acids extractions from these samples were performed with Roche MagNA Pure LC automated nucleic acid extraction system, using the MagNA Pure LC total nucleic acid isolation kit, according to the manufacturer's instructions (Roche $^{\mathrm{TM}}$ Basel, Switzerland) (Fig. 2). In brief, total nucleic acids were extracted and eluted in $50 \mu \mathrm{L}$ of elution buffer, directly from $250 \mu \mathrm{L}$ of each sample.

\section{Positive controls}

For DENV and WNV, reverse transcription reactions were carried out using SuperScript ${ }^{\circledR}$ III Reverse Transcriptase (Invitrogen ${ }^{\mathrm{TM}}$ Carlsbad USA). Viral cDNA and bacterial DNA were then amplified by PCR using TaqPol (Qiagen ${ }^{\mathrm{TM}}$ Hilden Germany) following manufacturer's instructions. In order to generate positive controls, PCR products were cloned into $\mathrm{PCR} 2.1$ vectors using the TOPO $^{\circledR}$ TA Cloning ${ }^{\circledR}$ Kit (Invitrogen ${ }^{\text {TM }}$ Carlsbad USA). In brief, $2 \mu \mathrm{L}$ of PCR product were mixed with $0.5 \mu \mathrm{L}$ of pCR2.1-TOPO vector, $0.5 \mu \mathrm{L}$ of $\mathrm{NaCl} 300 \mathrm{mM}, 0.5 \mu \mathrm{L}$ of $\mathrm{MgCl}_{2} 15 \mathrm{mM}$; after incubation for $10 \mathrm{~min}$, electrocompetent Escherichia coli TG1 were added and exposed to $1.5 \mathrm{kV}$ electric shock. Plasmidic DNA was extracted using 
Table 2 Conditions for RT-qPCR

\begin{tabular}{ll}
\hline Reversal transcription & Cycles: 1 \\
Temperature $\left({ }^{\circ} \mathrm{C}\right)$ & Time $($ min:s) \\
50 & $10: 00$ \\
Activation & Cycles : 1 \\
Temperature $\left({ }^{\circ} \mathrm{C}\right)$ & Time (min:s) \\
95 & $5: 00$ \\
PCR & Cycles : 40 \\
Temperature $\left({ }^{\circ} \mathrm{C}\right)$ & Time (min:s) \\
95 & $00: 10$ \\
60 & $00: 30$ \\
Melting curve & Cycles : 1 \\
Temperature $\left({ }^{\circ} \mathrm{C}\right)$ & Time (min:s) \\
95 & $00: 15$ \\
50 & $00: 15$ \\
95 & NA
\end{tabular}

NA not applies

QIAprep Spin Miniprep Kit (Qiagen ${ }^{\mathrm{TM}}$ Hilden German) and sequenced by the National Genomics Laboratory for Biodiversity (LANGEBIO, CINVESTAV). The individual controls were mixed together in order to generate a universal positive control with equal Cycle thresholds $\left(C_{t}\right)$ for each assay. This was achieved by running a gradient from $10^{6}$ to $10^{1}$ molecules of target copies for each set of primers in $\mathrm{qPCR}$ reaction. Then we calculated the necessary number of each control to amplify in Ct 22 .

\section{Analytical sensitivity and specificity}

In order to evaluate the analytical sensitivity, the range of linear detection for each RT-qPCR assay was calculated performing serial dilutions from $10^{6}$ up to $10^{0}$ molecules of each positive control per reaction. Additionally, the limit of detection (LOD) was calculated for each RTqPCR assay by PROBIT analysis. Ten replicas of RTqPCR amplifications were carried out using solutions with $100,50,10$ and 1 molecules/ $\mu \mathrm{L}$ of each positive control plasmid; $1 \mu \mathrm{L}$ of each solution was added per replica. The molecular weight of each plasmid with the insert, were used to calculate the number of plasmid molecules in the solutions.

To assess the analytical specificity of the four sets of primers in silico, BLAST analysis was conducted. To discard cross-reactivity, RT-qPCRs assays were performed with primers for WNV, Rickettsia and Leptospira using RNA from DENV2 and Homo sapiens, as well as DNA from Leptospira interrogans, Rickettsia canadensis and $H$. sapiens. The DENV primers were previously tested for cross-reactivity (Lai et al. 2007).

\section{Lyophilization assays}

In order to simplify the process of sample analysis, and diminish the time required for qPCR, we lyophilized all the reagents with rickettsia primers (as an example of primers), using four different cryoprotectors treatments. This experiment was required to test the stability of the reverse transcriptase and polymerase enzymes after the lyophilization process and not for the primers stability, since they are commercially distributed in this presentation. Treatments were: trehalose $0 \%$, trehalose $2.5 \%$ $\mathrm{w} / \mathrm{v}$, trehalose $5 \% \mathrm{w} / \mathrm{v}$ and trehalose $10 \% \mathrm{w} / \mathrm{v}$. The plate containing the reactions was incubated at $-80{ }^{\circ} \mathrm{C}$ overnight, and then maintained in a lyophilization chamber for $24 \mathrm{~h}$ at a pressure lower than $0.133 \mathrm{mBar}$ at $-40 \mathrm{C}$.

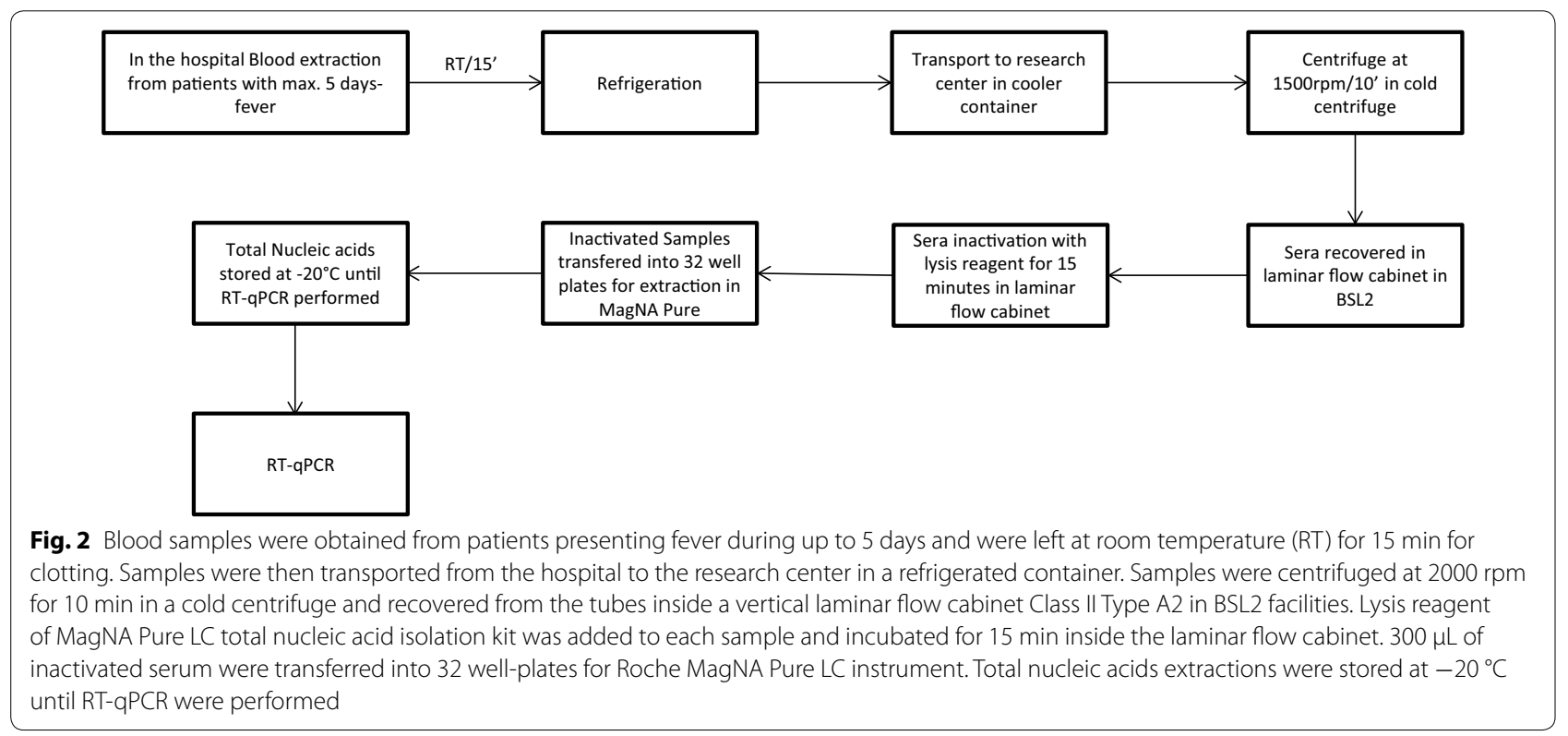


After lyophilization, a fresh reaction without cryoprotectors was included as a positive control.

\section{Statistical analysis}

Sample size was calculated using a confidence level of 95 and $10 \%$ margin of error for the DENV-positive cases in the metropolitan area of Guadalajara, Jalisco, Mexico, in 2014 ('Secretaria de Salud del Estado de Jalisco. Prevención Dengue' 2015). Statistical analysis for qPCR assays were performed as follows: efficiency was calculated in the Roche LightCycler 480 II software, linearity range and regression analysis were determined by Microsoft Excel 2013, and LOD was estimated by Probit analysis using MedCalc software for Windows version 16.4 (MedCalc Software, Ostend, Belgium).

\section{Results}

Primers

For DENV we used primers reported by Lai et al. (2007); these primers amplify a 258 bp fragment of the $3^{\prime}$ untranslated region. For WNV, Rickettsia spp. and Leptospira spp, a pair of primers was designed in order to amplify conserved regions of each agent. The WNV primers target a $210 \mathrm{bp}$ region of the gene coding for the envelope protein, Leptospire primers amplify a $297 \mathrm{bp}$ region of 16 rrs gene and Rickettsia primers, amplify an $83 \mathrm{bp}$ region of the gltA gene. These primers are predicted to identify hundreds of strains reported for each pathogen (Table 3).

\section{Analytical sensitivity and specificity}

In order to evaluate the analytical sensitivity of each assay, standard curves were generated by plotting the threshold cycle of each positive control against the concentration measured in copies $/ \mu \mathrm{L}$. Linearity of the assays in this study and their correlation coefficients were as follows: WNV $\left(\mathrm{r}^{2}=0.9891\right)$, Rickettsia $\left(\mathrm{r}^{2}=0.9994\right)$ and Leptospira $\left(\mathrm{r}^{2}=0.9795\right)$ ranged from $10^{1}$ to $10^{6}$ molecules, while for DENV $\left(\mathrm{r}^{2}=0.9816\right)$ the range was $10^{2}$ to $10^{6}$ molecules (Fig. 3). Four dilutions of positive controls were used as substrate to calculate the LOD with $95 \%$ probability for each pathogen. The LOD for DENV was 35.30, for WNV 33.50, for Rickettsia 11.19, and for Leptospira 27.43 molecules.

The analytical specificity was evaluated by primerBLAST. The analysis did not retrieve sequences of other unintended species. Furthermore, this analysis retrieved 1876 strains for DENV, 1000 for WNV, 302 for Rickettsia spp. and 479 for Leptospira spp. (Table 3). No crossreactivity was detected in WNV, Leptospira or Rickettsia assays.

\section{Lyophilization assays}

The fresh positive control reaction showed a $C_{t}$ of 22 while the $C_{t}$ of $0,2.5,5$ and $10 \%$ of trehalose treatments were 24, 26, 29 and 33, respectively (Fig. 4). All lyophilized treatments showed a drop in the maximum fluorescence, however, the lyophilized reaction without trehalose showed a smaller drop in fluorescence.

\section{Analysis of clinical samples}

We performed a pre-validation of the diagnostic strategy presented herein, using 100 sera samples from patients with dengue-like symptoms collected during the last DENV outbreak (June-Nov 2015). From the 100 samples, 12 were positive for DENV and one sample was positive for leptospirosis. None of them were positive for rickettsiosis or WNV.

\section{Discussion}

DENV, WNV, Rickettsia spp. and Leptospira spp. may coexist in warm and moist regions around the world, but often in Latin-American countries, only Dengue Fever has been recognized as a health problem. Because of this, we have developed a qPCR system that is intended for use in Latin American countries, where these four pathogens have been reported (e.g. Mexico). Since these pathogens produce similar symptoms and are circulating throughout the continent (Beeler et al. 2011; Elizondo-Quiroga et al. 2005; Gorrochotegui-Escalante et al. 2002; IbarraJuarez et al. 2012; Romer et al. 2011; Zavala-Velázquez et al. 1998), the actual number of infections might be currently misdiagnosed and treated only as Dengue Fever. Although cross reactivity between these viruses has been reported in immunological tests (Papin et al. 2004), and DENV and leptospirosis have been repeatedly confused (Brown et al. 2010; Ellis et al. 2008; LaRocque et al. 2005; Libraty et al. 2007; Papin et al. 2004), differential diagnostics is rarely conducted in these countries.

Individual DNA diagnostics have previously shown that nucleic acids of these four pathogens, can be found in serum samples only during the first 5 days of these diseases, and this also happens to be the most crucial time for diagnostic in patients, since severe complications or spontaneous resolution of the disease occur after the first week of the apparition of symptoms. After this time frame, antibodies can be found and serological tests can be used instead of molecular technics.

We have also developed a simultaneous qPCR-based system that uses novel primers for WNV, Rickettsia spp. and Leptospira spp., predicted to amplify most circulating strains of each agent and a pair of previously reported DENV primers. These four pairs of primers are able to amplify target sequences under the same PCR conditions. 
Table 3 Number of retrieved sequences for each specie, genome species or type of virus; in Rickettsia spp., symbionts and endosymbionts were not included

\begin{tabular}{|c|c|c|}
\hline Disease & Agent & $\begin{array}{l}\text { Number of retrieved } \\
\text { sequences }\end{array}$ \\
\hline \multirow[t]{43}{*}{ Rickettsiosis } & R. prowazekii & 12 \\
\hline & R. rickettsii & 15 \\
\hline & R. typhi & 4 \\
\hline & Israeli tick typhus rickettsia & 3 \\
\hline & R. felis & 3 \\
\hline & R. conorii & 5 \\
\hline & R. parkeri & 5 \\
\hline & R. rhipicephali & 3 \\
\hline & R. akari & 2 \\
\hline & R. honei & 2 \\
\hline & R. canadensis & 4 \\
\hline & R. bellii & 11 \\
\hline & R. massiliae & 5 \\
\hline & Candidatus R. amblyommii & 6 \\
\hline & R. montanensis & 1 \\
\hline & R. slovaca & 5 \\
\hline & R. peacockii & 2 \\
\hline & R. monacensis & 1 \\
\hline & R. tamurae & 1 \\
\hline & R. tarasevichiae & 4 \\
\hline & R.philipii & 1 \\
\hline & R. africae & 6 \\
\hline & R. japonica & 2 \\
\hline & R. heilongjiangensis & 7 \\
\hline & R. aeschlimannii & 10 \\
\hline & R. sibirica & 4 \\
\hline & Candidatus R. andeanae & 2 \\
\hline & R. mongolotimonae & 1 \\
\hline & Candidatus R. kulagini & 1 \\
\hline & R.marmionii & 1 \\
\hline & R. montana & 1 \\
\hline & Candidatus R. antechini & 1 \\
\hline & Candidatus R. gravesii & 1 \\
\hline & R. raoultii & 29 \\
\hline & R. australis & 1 \\
\hline & Candidatus R. rioja & 1 \\
\hline & Candidatus R.tasmanensis & 2 \\
\hline & R. asiatica & 5 \\
\hline & Candidatus R. rara & 1 \\
\hline & Candidatus R. uilenbergi & 1 \\
\hline & Candidatus R. davousti & 1 \\
\hline & Candidatus R. hoogstraalii & 1 \\
\hline & R. helvetica & 1 \\
\hline \multirow[t]{4}{*}{ Leptospirosis } & L. interrogans & 178 \\
\hline & L. borgpeterseni & 64 \\
\hline & L. santarosai & 21 \\
\hline & L. noguchii & 18 \\
\hline
\end{tabular}

Table 3 continued

\begin{tabular}{|c|c|c|}
\hline Disease & Agent & $\begin{array}{l}\text { Number of retrieved } \\
\text { sequences }\end{array}$ \\
\hline & L. weilii & 14 \\
\hline & L. alexanderi & 5 \\
\hline & L. kirschneri & 29 \\
\hline & L. inadai & 5 \\
\hline & L.meyeri & 8 \\
\hline & L.fainei & 6 \\
\hline & L.broomii & 4 \\
\hline & L. biflexa & 16 \\
\hline & L. wolffii & 2 \\
\hline & L. idonii & 1 \\
\hline & L. licerasiae & 10 \\
\hline & L. kmetyi & 1 \\
\hline & L.wolbachi & 3 \\
\hline & Leptospira sp. & 94 \\
\hline \multirow[t]{4}{*}{ Dengue fever } & DENV 1 & 553 \\
\hline & DENV 2 & 821 \\
\hline & DENV 3 & 356 \\
\hline & DENV 4 & 148 \\
\hline West Nile fever & WNV & 1000 \\
\hline
\end{tabular}

Additionally, since primers amplify conserved regions across strains of these four pathogens, the diagnostic result indicates the disease in the patient or sample, no matter the species or strain involved in the infection.

We employ cDNA controls for DENV and WNV assay, since assessing the analytical sensitivity using a constructed standard curve with viral titers would be prone to over-estimation given that viable and non-viable particles are detected. Researchers have also used cloned positive controls to determine the sensitivity of their tests (Hull et al. 2008; Kang et al. 2010), but this does not include the efficiency of reverse transcription and extraction process; therefore for diagnostic laboratories, we suggest to solve these drawbacks by using RNA from positive samples as controls.

In the analytical sensitivity estimations, we found a wide linear range of detection for our RT-qPCR assays and LODs of 35.30 copies for DENV, 33.50 copies for WNV, 11.19 copies for Rickettsia and 27.43 copies for Leptospira. Previous reports for DENV (Kim et al. 2015), for WNV (Linke et al. 2007), for Rickettsia (Renvoisé et al. 2012) and for Leptospira (Ferreira et al. 2014) have shown similar sensitivities. We have confirmed the selectivity using in silico tests, thus ruling out possible amplifications due to DNA of other microorganisms. Additionally, primers for DENV reported by Lai et al. showed no amplifications when tested against nonDENV RNA. Although our work has shown promising 



results so far to diagnose DENV and Leptospira spp., we have not been able to analyze this assay with positive samples from patients positive to Rickettsia spp. and WNV.

Dengue fever has emerged as a constant health threat to the population of Jalisco state, Mexico. According to official reports from Health Secretariat, 1229 cases of Dengue fever were reported during 2014 in this state, out of which 220 were from the metropolitan area.
('Secretaria de Salud del Estado de Jalisco. Prevención Dengue' 2015). In this work, out of 100 sera samples from patients with dengue-like symptoms, we found 12 positive to DENV in a period of 6 months from a single hospital. We additionally found one sample positive for leptospirosis. Interestingly, there were no official reports of any leptospirosis case for Jalisco state in 2015 (Boletin Epidemiológico. Semana 52. Secretaría de Salud. 2016). In this study, we found no positive cases for WNV or 
rickettsiosis. From the total of samples, 87 were negative to the four diseases comprised in our diagnostic strategy; this could be due to inaccurate information provided by the patient to the health personnel of the hospital. Another possible explanation is the recent introduction of the Chikungunya virus into Mexico (Rivera-Avila 2014); since it is also an arbovirus that produces dengue-like symptoms and a very high attack rate has been reported (Renault et al. 2007) it is likely that some of the patients enrolled in this study, could have been infected with this virus.

Finally, we designed a prototype device consisting of a 96 well plate in which all necessary reagents for PCR, excluding nucleic acids, were added to each well and lyophilized. Every four wells of this device include the specific set of primers for DENV, WNV, Rickettsia spp. and Leptospira spp. According to this prototype, each sample must be added to a set of four wells in order to identify the nucleic acids in it. One plate can analyze up to 22 samples, one negative control and one positive control (Fig. 1).

Lyophilization of reagents into the plate provides several benefits: (a) it enhances the reproducibility of results, (b) it reduces the set-up time for reactions, (c) it reduces the risk of contamination and false positives, (d) it easies transport and storage of the plate. Apparently, components in the enzyme buffer are also a good cryo-protector and there is no need for additional enhancers to stabilize it during the processing of samples.

\section{Conclusions}

At the moment the molecular differential diagnostic technic is necessary to clearly comprehend the epidemiological relevance of these diseases in some areas and may aid health secretariats and vector control departments to better aim their resources for effective management of outbreaks. Also, quick diagnosis will help to prescribe correct antibiotics for bacterial-origin fever, and a careful follow-up for fevers caused by DENV or WNV, therefore we are presenting a sensitive and selective kit that detects four relevant pathogens from tropical regions, that is also quick, cost-effective and easy to use.

\section{Authors' contributions}

$\mathrm{DG}, \mathrm{MM}, \mathrm{AC}$, carried out molecular genetic studies, participated in the sequence alignment and drafted and reviewed the manuscript. EM, AG, designed part of the experiments and reviewed the manuscript. EM, EG, RM, $E R, H P$, participated in sample collection and reviewed the manuscript, $D E$, designed experiments, conceived the project, and drafted and reviewed the manuscript. All authors read and approved the final manuscript.

\section{Author details}

1 Dirección de Biotecnología Médica y Farmacéutica, Centro de Investigación y Asistencia en Tecnología y Diseño del Estado de Jalisco (CIATEJ), Avenida Normalistas No. 800, Colinas de la Normal, C.P. 44270 Guadalajara, Jalisco, Mexico. ${ }^{2}$ Departamento de Infectología, Hospital Civil Fray Antonio Alcalde, Calle Hospital No. 270, El Retiro, 44200 Guadalajara, Jalisco, Mexico.

\section{Acknowledgements}

This project was financially supported with funds provided by the Fondo Sectorial de Investigación en Salud Grant: SALUD-161864. Flor Y. Flores Hernández provided the WNV vaccine from the Conservation Medicine Lab (Escuela superior de Medicina, Instituto Politécnico Nacional). Also, we would like to thank Dr. Jorge Zavala-Castro of CIR, UADY (Centro de Investigaciones Regionales Dr. Hideyo Noguchi de la Universidad Autonoma de Yucatán) for providing an inactivated sample of Rickettsia parkeri. Also, we thank Tina Kim Coop (Peace Corps Volunteer) for her assistance in the English language revision of the manuscript.

\section{Competing interests}

The authors declare that they have no competing interests.

Received: 29 December 2015 Accepted: 10 May 2016

Published online: 20 May 2016

\section{References}

Bäck AT, Lundkvist Å (2013) Dengue viruses_an overview. Infect Ecol Epidemiol 3:1-21

Beeler E, Abramowicz KF, Zambrano ML, Sturgeon MM, Khalaf N, Hu R, Dasch GA, Eremeeva ME (2011) A focus of dogs and Rickettsia massiliae-infected Rhipicephalus sanguineus in California. Am J Trop Med Hyg 84:244-249

Boletín Epidemiológico. Semana 52. Secretaría de Salud. (2016) Mexico DF, Mexico

Brown M, Vickers I, Salas R, Smikle M (2010) Leptospirosis in suspected cases of dengue in Jamaica, 2002-2007. Trop Doct 40:92-94

Colpitts TM, Conway MJ, Montgomery RR, Fikrig E (2012) West Nile virus: biology, transmission, and human infection. Clin Microbiol Rev 25:635-648

Cota GF, de Sousa MR, Demarqui FN, Rabello A (2012) The diagnostic accuracy of serologic and molecular methods for detecting visceral leishmaniasis in HIV infected patients: meta-analysis. PLoS Negl Trop Dis 6(5):e1665. doi:10.1371/journal.pntd.0001665

Denison AM, Amin BD, Nicholson WL, Paddock CD (2014) Detection of Rickettsia rickettsii, Rickettsia parkeri, and Rickettsia akari in skin biopsy specimens using a multiplex real-time polymerase chain reaction assay. Clin Infect Dis 59:635-642

Elizondo-Quiroga D, Davis CT, Fernandez-salas I et al (2005) West nile virus isolation in human and mosquitoes, Mexico. R Soc 11:1449-1452

Ellis T, Imrie A, Katz A, Effler P (2008) Underrecognition of leptospirosis during a dengue fever outbreak in Hawaii, 2001-2002. Vector Borne Zoonotic Dis 8:541-547

Ferreira AS, Costa P, Rocha T, et al (2014) Direct detection and differentiation of pathogenic Leptospira species using a multi-gene targeted real time PCR approach. PLoS One 9(11):e112312. doi:10.1371/journal. pone. 0112312

Gorrochotegui-Escalante N, Gomez-Machorro C, Lozano-Fuentes S et al (2002) Breeding structure of aedes aegypti populations in Mexico varies by region. Am J Trop Med Hyg 66:213-222

Howson ELA, Armson B, Madi M, Kasanga CJ, Kandusi S, Sallu R, Chepkwony E, Siddle A, Martin P, Wood J, Mioulet V, King DP, Lembo T, Cleaveland S, Fowler VL (2015) Evaluation of two lyophilized molecular assays to rapidly detect foot-and-mouth disease virus directly from clinical samples in field settings. Transbound Emerg Dis. doi:10.1111/tbed.12451

Hull R, Nattanmai S, Kramer LD, Bernard KA, Tavakoli NP (2008) A duplex real-time RT-PCR assay for the detection of St. Louis encephalitis and Eastern equine encephalitis viruses. Diagn Microbiol Infect Dis 62:272-279

Ibarra-Juarez L, Eisen L, Bolling BG, Beaty BJ, Blitvich BJ, Sanchez-Casas RM, Ayala-Sulca YO, Fernandez-Salas I (2012) Detection of West Nile virus-specific antibodies and nucleic acid in horses and mosquitoes, respectively, in Nuevo Leon State, northern Mexico, 2006-2007. Med Vet Entomol 26:351-354

Kamau E, Alemayehu S, Feghali KC et al (2014) Sample-ready multiplex qPCR assay for detection of malaria. Malar J 13:158

Kang X, Li Y, Liu H et al (2010) A duplex real-time reverse transcriptase polymerase chain reaction assay for detecting western equine and eastern equine encephalitis viruses. Virol J 7:284 
Kim JH, Chong CK, Sinniah M, Sinnadurai J, Song HO, Park H (2015) Clinical diagnosis of early dengue infection by novel one-step multiplex real-time RT-PCR targeting NS1 gene. J Clin Virol 65:11-19

Lai YL, Chung YK, Tan HC, Yap HF, Yap G, Ooi EE, Ng LC (2007) Cost-effective real-time reverse transcriptase PCR (RT-PCR) to screen for dengue virus followed by rapid single-tube multiplex RT-PCR for serotyping of the virus. J Clin Microbiol 45:935-941

LaRocque RC, Breiman RF, Ari MD et al (2005) Leptospirosis during dengue outbreak, Bangladesh. Emerg Infect Dis 11:766-769

Lee SV, Tai ES, Mutalib AR, Khairani-Bejo S, Bahaman AR (2011) Rapid detection of pathogenic leptospires by lyophilized reagent-based polymerase chain reaction. Trop Biomed 28:497-505

Levett PN (2001) Leptospirosis. Clin Microbiol 14:296-326

Levett PN, Branch SL, Edwards CN (2000) Detection of dengue infection in patients investigated for leptospirosis in Barbados. Am J Trop Med Hyg 62:112-114

Li S, Fang M, Zhou B et al (2011) Simultaneous detection and differentiation of dengue virus serotypes 1-4, Japanese encephalitis virus, and West Nile virus by a combined reverse-transcription loop-mediated isothermal amplification assay. Virol J 8:360

Libraty DH, Myint KSA, Murray CK et al (2007) A comparative study of leptospirosis and dengue in Thai children. PLoS Negl Trop Dis 1:1-7

Linke S, Ellerbrok H, Niedrig M, Nitsche A, Pauli G (2007) Detection of West Nile virus lineages 1 and 2 by real-time PCR. J Virol Methods 146:355-358

Lins RD, Pereira CS, Hu PH (2004) Trehalose-protein interaction in aqueous solution. Appl Biochem Microbiol 186:177-186

Mahajan SK (2012) Rickettsial diseases. J Assoc Physicians India 60:37-44

Ohtake S, Wang J (2011) Trehalose, current use and future applications. J Pharm Sci 99:2020-2053
Papin JF, Vahrson W, Dittmer DP (2004) SYBR green-based real-time quantitative PCR assay for detection of West Nile virus circumvents false-negative results due to strain variability SYBR green-based real-time quantitative PCR assay for detection of West Nile virus circumvents false-negative R. J Clin Microbiol 42:1511-1518

Petersen LR, Marfin A (2002) Review West Nile Virus: a primer for the clinician. Ann Intern Med 137:173-179

Renault P, Solet J, Sissoko D et al (2007) A major epidemic of chikungunya virus infection on Réunion Island 77:727-731

Rivera-Avila RC (2014) Fiebre chikugunya en Mexico: caso confirmado y apuntes para la respuesta epidemiologica. Salud Publica de Mexico 56:402-404

Renvoisé A, Rolain J-MJ, Socolovschi C, Raoult D (2012) Widespread use of real-time PCR for rickettsial diagnosis. FEMS Immunol Med Microbiol 64:126-129

Romer Y, Seijo AC, Crudo F, Nicholson WL, Varela-Stokes A, Ryan Lash R, Paddock CD (2011) Rickettsia parkeri rickettsiosis, Argentina. Emerg Infect Dis 17:1169-1173

Sahni SK, Rydkina E (2009) Host-cell interactions with pathogenic Rickettsia species. Future Microbiol 4:323-339

Secretaria de Salud del Estado de Jalisco. Prevención Dengue (2015). http:// prevenciondengue.jalisco.gob.mx/index.html

World Health Organization (2009) Dengue: guidelines for diagnosis, treatment, prevention, and control. World Health Organization, Special Programme for Research and Training in Tropical Diseases

Zavala-Velázquez JE, Vado-Solis IA, Rodriguez-Félix ME, Rodriguez-Angulo EM, Barrera-Pérez MA, Guzman-Marín E del S (1998) Leptospirosis anictérica en un brote epidémico de dengue en la Península de Yucatan. Rev Biomed 9:78-83

\section{Submit your manuscript to a SpringerOpen ${ }^{\odot}$ journal and benefit from:}

- Convenient online submission

- Rigorous peer review

- Immediate publication on acceptance

- Open access: articles freely available online

- High visibility within the field

- Retaining the copyright to your article

Submit your next manuscript at springeropen.com 